\title{
Preoperative pillow placement under the injured extremity had better analgesic effects than skin traction for hip fracture
}

\author{
Rosen JE, Chen FS, Hiebert R, et al. Efficacy of preoperative skin traction in hip fracture patients: a prospective, \\ randomized study.J Orthop Trauma 2001 Feb;15:81-5.
}
QUESTION: What is the comparative analgesic effectiveness of preoperative placement of a pillow under the injured extremity and skin traction in patients with hip fracture?

Design

Randomised (unclear allocation concealment), unblinded trial with follow up at 15 minutes and 1 day after the intervention.

Setting

A university medical centre in New York, USA.

\section{Patients}

100 patients aged $\geqslant 50$ years (mean age 78 y, $78 \%$ women) with an isolated femoral neck fracture $(n=55)$ or intertrochanteric hip fracture $(n=45)$. Exclusion criteria included dementia, concomitant injury, delayed hospital presentation ( $>24 \mathrm{~h}$ after initial injury), or inadequate cognitive function. $96 \%$ of patients had follow up on the morning after the intervention.

\section{Intervention}

Preoperatively, patients were allocated to have a pillow placed under the ipsilateral thigh of the injured hip in the resting position of the extremity ( $\mathrm{n}=50$, pillow group) or to placement of 5 pounds of skin traction, applied by fitting a foam traction boot to the injured extremity and then suspending a 5 pound weight over a pulley at the foot of the bed ( $\mathrm{n}=50$, traction group). All patients received standardised pain medication as needed.

\section{Main outcome measure}

Patient self reported pain was assessed on a 10 point visual analogue scale (VAS) (range $0=$ no pain to $10=$ extreme pain)

\section{Main results}

15 minutes after the intervention, no difference existed in pain reduction from baseline between patients in the pillow group and those in the traction group (mean reduction scores on the VAS $1.44 v 1.24, \mathrm{p}=0.6$ ). On the morning after the intervention, patients in the pillow group experienced greater pain reduction from baseline than those in the traction group (mean reduction scores on the VAS $2.82 v 1.76, \mathrm{p}=0.04)$.

\section{Conclusion}

In patients with hip fracture, pillow placement under the injured extremity and preoperative skin traction had similar immediate analgesic effects, but pillow placement was more effective in reducing pain on the morning after the intervention.
Source of funding: no external funding.

For correspondence: Dr K J Koval,

Department of

Orthopaedic Surgery, The

Hospital for Joint

Diseases, New York
University Medical

Center, 301 East 17th

Street, New York, NY

10003, USA. Fax +1

2125986015

\section{COMMENTARY}

Until the introduction of surgery in the 1950 's, skin traction was the traditional treatment for a proximal femoral fracture. In some situations, skin traction is still used, with the aims of reducing preoperative pain, preventing further tissue damage, and easing intra operative reduction of the fracture.

Skin traction, however, has potential complications. Rosen et al recognised the discomfort caused by its application and the potential for the development of pressure sores. Their randomised study measured the analgesic effects of pillow support compared with skin traction before surgery for hip fracture and found that pillow support of the affected limb produced better pain relief. Weaknesses of the study are lack of blinding of patients, clinicians, and outcome assessors, and strengths include the randomised design and good statistical power.

A Cochrane review of trials comparing skin traction with skeletal traction or no traction before surgery for hip fracture concluded that skin traction does not have any benefits. ${ }^{1}$ Only 3 randomised controlled trials in the review compared skin traction with pillow support; 2 of these measured pain and 1 found a reduction in VAS score associated with skin traction. The study by Rosen et al lends weight to the conclusion of the review and finds a reduction in pain associated with pillow support combined with reduced use of pharmacological analgesia. Little evidence exists to show the effect of limb position on pain control after a femoral fracture. Previous studies suggest that slight flexion, ${ }^{2}{ }^{3}$ abduction, and external rotation of the hip will result in a reduction of intracapsular pressure and, therefore, also pain. The most comfortable resting position can be maintained by limb support.

Future research should address other perceived benefits of traction such as the ease of intra operative fracture reduction; the current evidence however, suggests that skin traction does not confer short term benefits.

Pauline Barnes, RGN, MSc Nurse Clinician St Helens E Knowsley Hospital Trust Merseyside, UK

1 Parker MJ, Handoll HH. Preoperative traction for fractures of the proximal femur. Cochrane Database Syst Rev 2001;(2):CD000168.

2 Maruenda JI, Barrios C, Gomar-Sancho F. Intracapsular hip pressure after femoral neck fracture. Clin Orthop 1997;340:172-80.

3 Stromqvist B, Nilsson LT, Egund N, et al. Intracapsular pressures in undisplaced fractures of the femoral neck. J Bone Joint Surg Br 1988;70:192-4 